\title{
Three-Dimensional Mixed Convection Flow past an Infinite Vertical Plate with Constant Surface Heat Flux
}

\author{
Bhupendra Kumar Sharma ${ }^{1, *}$, Tara Chand ${ }^{2}$, R. C. Chaudhary ${ }^{2}$ \\ ${ }^{1}$ Department of Mathematics, Birla Institute of Technology \& Science, Pilani, -333031 (India) \\ ${ }^{2}$ Department of Mathematics, University of Rajasthan, Jaipur-302004 (India)
}

\begin{abstract}
The present paper contains a mathematical analysis of the mixed convection three dimensional steady laminar flow of a viscous incompressible fluid past an infinite vertical porous plate. The three-dimensional flow is caused by the transverse sinusoidal suction at the plate. A constant heat flux is prescribed at the plate. Assuming the plate velocity to be uniform, analytical solutions are obtained for the flow field, the temperature field and the skin-friction. Effects of Prandtl number and Grashof number on the flow characteristics are explored and illustrated graphically.
\end{abstract}

Keywords Three Dimensional, Mixed Convection, Heat Flux

\section{Introduction}

In view of the importance of the problems of laminar flow control (LFC), especially in the field of aeronautical engineering, various theoretical and experimental studies of different arrangements and configurations of suction holes and slits have been compiled by Lachmann[1]. The suction of the fluid is also an acknowledged technique for controlling the undesirable features in the boundary layer theory. Further, from the technological point of view, free convection flow and heat transfer problems are always important, for they have many practical applications. The phenomenon of free-convection arises when the difference between the plate temperature and the free stream temperature appreciably large which causes density variations leading to buoyancy forces acting on the fluid elements. This process of heat transfer is encountered in cooling of nuclear reactors, providing heat sinks in turbine blades and aeronautics. Free convection flow past vertical plate has been studied extensively by many researchers and some of them are Ostrach[2-3], Stewartson et. al.[4], Sparrow et. al.[5-6], Mabuchi[7], Riley et. al.[8], Berezovsky et.al.[9], $\mathrm{Na}[10]$, Dey et al [11], Kawase et al[12], Martynenko et.al.[13], Weiss et.al.[14] and Pantokratoras[15-16] in numerous ways to include various physical effects. In their work they have restricted themselves to two-dimensional flow only. There may arise situations where the flow fields may be essentially three-dimensional, for example when variations in the suction velocity distribution is transverse to the flow direction. Gersten and Gross[17] have studied the effect of such

* Corresponding author:

bhupen_1402@yahoo.co.in (Bhupendra Kumar Sharma)

Published online at http://journal.sapub.org/ajcam

Copyright (C) 2011 Scientific \& Academic Publishing. All Rights Reserved a transverse sinusoidal suction velocity distribution on flow and heat transfer over a plane wall. Singh et.al[18] extended the idea of transverse suction velocity further to vertical porous plate. In references[17-18] the temperature of the plate was kept constant.

In many problems, particularly those involving the cooling of electrical and nuclear components, the wall heat flux is specified. In such problems, over heating burnout and meltdown are very important issues. From practical stand point, an important wall model is considered with constant heat flux. In many applications, the wall heating effect is the result of radiation heating (the constant heat flux condition applies to nuclear radiation heating) from the other side or, as in the case of electronic components, the result of resistive heating (Bejan[19] ). The problems with prescribed heat flux are special cases of the vast analytically accessible class of problems. Sparrow et al[6], Merkin et al[20], Lee.et al.[21], Malarvizhi et.al.[22], Burak et. al.[23] and Pantokratoras[24] are some of the researchers who have investigated the convection flow with prescribed heat flux conditions. Injection and suction effects on three dimensional unsteady flow and heat transfer between two parallel porous plates have been studied by Chaudhary and Sharma[25]. Sharma et. al.[26] have studied the radiation effect on temperature distribution in three-dimensional Couette flow with injection or suction. Recently, three-dimensional unsteady mixed convection flow with periodic temperature studied by Sharma et. al.[27-29].

Approximate solutions of physical problems are handy tools in the hands of a scientist and an engineer. Though the advent of computers has opened new vistas for obtaining accurate numerical solutions of the problems of ever-increasing complexity, it has in no way diminished the utility of a judiciously produced approximate analytical solutions which are also fairly accurate. 
In the present paper, we present an approximate analytical solution to the problem of the laminar three-dimensional (caused by sinusoidally varying suction) steady mixed convection flow past an infinite vertical porous plate with constant heat flux, (CHF), from which the fluid is extracted at a uniform rate.

\section{Mathematical Analysis}

We choose a coordinate system with plate lying vertically on $\mathrm{x}^{*}-\mathrm{z}^{*}$ plane such that $\mathrm{x}^{*}$-axis is oriented in direction of the buoyancy force and $\mathrm{y}^{*}$-axis is perpendicular to the plane of the wall and directed into the fluid. The wall is moving with constant velocity $\mathrm{U}_{0}$. A constant suction velocity at the plane then leads to the two-dimensional asymptotic suction solution and the suction velocity transverse to the flow directions leads to cross-flow and hence the flow will be three-dimensional over the entire plane. We consider the sinusoidal suction velocity distribution of the form

$$
\mathrm{v}^{*}\left(\mathrm{z}^{*}\right)=-\mathrm{V}_{0}\left(1+\varepsilon \cos \pi \frac{\mathrm{V}_{0} \mathrm{z}^{*}}{\mathrm{v}}\right)
$$

where $\mathrm{V}_{0}>0$ is the constant mean suction velocity; $v$ is the kinematics viscosity and $\varepsilon(<<1)$ is the amplitude of the sinusoidal suction velocity. The negative sign in equation (1) indicates that the suction is towards the plate. Although, the velocity and temperature fields will be independent of $x^{*}$ because an asymptotic flow has been taken, the flow field itself will be three-dimensional due to the cross-flow. Denoting velocity components $u^{*}, v^{*}, w^{*}$ in the $x^{*}, y^{*}$, $\mathrm{z}^{*}$-directions, respectively and temperature $\mathrm{T}^{*}$. The flow is governed by the following equations under the usual Boussinesq approximations:

Continuity equation

$$
\frac{\partial \mathrm{v}^{*}}{\partial \mathrm{y}^{*}}+\frac{\partial \mathrm{w}^{*}}{\partial \mathrm{z}^{*}}=0
$$

Momentum equations

$$
\begin{gathered}
\mathrm{v}^{*} \frac{\partial \mathrm{u}^{*}}{\partial \mathrm{y}^{*}}+\mathrm{w}^{*} \frac{\partial \mathrm{u}^{*}}{\partial \mathrm{z}^{*}}=\mathrm{g} \beta\left(\mathrm{T}^{*}-\mathrm{T}_{\infty}^{*}\right)+v\left(\frac{\partial^{2} \mathrm{u}^{*}}{\partial \mathrm{y}^{* 2}}+\frac{\partial^{2} \mathrm{u}^{*}}{\partial \mathrm{z}^{2}}\right) \\
\mathrm{v}^{*} \frac{\partial \mathrm{v}^{*}}{\partial \mathrm{y}^{*}}+\mathrm{w}^{*} \frac{\partial \mathrm{v}^{*}}{\partial \mathrm{z}^{*}}=-\frac{1}{\rho^{*}} \frac{\partial \mathrm{P}^{*}}{\partial \mathrm{y}^{*}}+v\left(\frac{\partial^{2} \mathrm{v}^{*}}{\partial \mathrm{y}^{* 2}}+\frac{\partial^{2} \mathrm{v}^{*}}{\partial \mathrm{z}^{* 2}}\right) \\
\mathrm{v}^{*} \frac{\partial \mathrm{w}^{*}}{\partial \mathrm{y}^{*}}+\mathrm{w}^{*} \frac{\partial \mathrm{w}^{*}}{\partial \mathrm{z}^{*}}=-\frac{1}{\rho^{*}} \frac{\partial \mathrm{P}^{*}}{\partial \mathrm{z}^{*}}+v\left(\frac{\partial^{2} \mathrm{w}^{*}}{\partial \mathrm{y}^{* 2}}+\frac{\partial^{2} \mathrm{w}^{*}}{\partial \mathrm{z}^{* 2}}\right)
\end{gathered}
$$

Energy equation

$$
\rho^{*}\left(\mathrm{v}^{*} \frac{\partial \mathrm{T}^{*}}{\partial \mathrm{y}^{*}}+\mathrm{w}^{*} \frac{\partial \mathrm{T}^{*}}{\partial \mathrm{z}^{*}}\right)=\kappa\left(\frac{\partial^{2} \mathrm{~T}^{*}}{\partial \mathrm{y}^{* 2}}+\frac{\partial^{2} \mathrm{~T}^{*}}{\partial \mathrm{z}^{* 2}}\right)
$$

where $C_{p}$ is the specific heat of the fluid at constant pressure; $\rho$ is the density; $\mathrm{p}^{*}$ is the pressure; $\mathrm{T}_{\infty}^{*}$ is the temperature in the free stream and $\kappa$ is the thermal conductivity. For $\beta \nabla T<<1$. We can express $\left(\rho_{\infty}^{*}-\rho^{*}\right)$ in terms of
$\left(\mathrm{T}^{*}-\mathrm{T}_{\infty}^{*}\right)$ as $\mathrm{g}\left(\rho_{\infty}^{*}-\rho^{*}\right)=\mathrm{g} \beta \rho^{*}\left(\mathrm{~T}^{*}-\mathrm{T}_{\infty}^{*}\right)$.

The boundary conditions are:

$$
\begin{aligned}
& \mathrm{y}^{*}=0: \mathrm{u}^{*}=\mathrm{U}_{0}, \mathrm{v}^{*}=-\mathrm{V}_{0}\left(1+\varepsilon \cos \pi \frac{\mathrm{V}_{0} \mathrm{z}^{*}}{v}\right), \\
& \mathrm{w}^{*}=0, \frac{\partial \mathrm{T}^{*}}{\partial \mathrm{y}^{*}}=-\frac{\mathrm{q}^{*}}{\kappa} \\
& \mathrm{y}^{*} \rightarrow \infty: \mathrm{u}^{*}=0: \mathrm{v}^{*}=-\mathrm{V}_{0}, \mathrm{w}^{*}=0, \mathrm{~T}^{*}=\mathrm{T}_{\infty}^{*}
\end{aligned}
$$

Here, $\mathrm{q}^{*}$ is the heat flux per unit area.

Introducing the following non-dimensional quantities:

$$
\begin{aligned}
& \mathrm{y}=\mathrm{V}_{0} \mathrm{y}^{*} / v, \mathrm{z}=\mathrm{V}_{0} \mathrm{z}^{*} / v, \mathrm{u}=\mathrm{u}^{*} / \mathrm{U}_{0}, \\
& \mathrm{v}=\mathrm{v}^{*} / \mathrm{V}_{0}, \mathrm{w}=\mathrm{w}^{*} / \mathrm{V}_{0}, \mathrm{P}=\mathrm{P}^{*} / \rho^{*} \mathrm{~V}_{0}^{2}, \\
& \theta=\left(\mathrm{T}^{*}-\mathrm{T}_{\infty}^{*}\right) \mathrm{V}_{0} \kappa / \mathrm{q}^{*} v \\
& \mathrm{Pr}=\frac{\mathrm{mC}_{\mathrm{p}}}{\kappa}, \text { the Prandtl number, } \\
& \mathrm{Gr}=\frac{\mathrm{g} \beta \mathrm{q}^{*} v^{2}}{\kappa \mathrm{V}_{0}^{3} \mathrm{U}_{0}}, \text { the Grashof number. }
\end{aligned}
$$

The equations (2) to (7) become

$$
\begin{gathered}
\frac{\partial \mathrm{v}}{\partial \mathrm{y}}+\frac{\partial \mathrm{w}}{\partial \mathrm{z}}=0 \\
\mathrm{v} \frac{\partial \mathrm{u}}{\partial \mathrm{y}}+\mathrm{w} \frac{\partial \mathrm{u}}{\partial \mathrm{z}}=\operatorname{Gr} \theta+\left(\frac{\partial^{2} \mathrm{u}}{\partial \mathrm{y}^{2}}+\frac{\partial^{2} \mathrm{u}}{\partial \mathrm{z}^{2}}\right) \\
\mathrm{v} \frac{\partial \mathrm{v}}{\partial \mathrm{y}}+\mathrm{w} \frac{\partial \mathrm{v}}{\partial \mathrm{z}}=-\frac{\partial \mathrm{P}}{\partial \mathrm{y}}+\left(\frac{\partial^{2} \mathrm{v}}{\partial \mathrm{y}^{2}}+\frac{\partial^{2} \mathrm{v}}{\partial \mathrm{z}^{2}}\right) \\
\mathrm{v} \frac{\partial \mathrm{w}}{\partial \mathrm{y}}+\mathrm{w} \frac{\partial \mathrm{w}}{\partial \mathrm{z}}=-\frac{\partial \mathrm{P}}{\partial \mathrm{z}}+\left(\frac{\partial^{2} \mathrm{w}}{\partial \mathrm{y}^{2}}+\frac{\partial^{2} \mathrm{w}}{\partial \mathrm{z}^{2}}\right) \\
\mathrm{v} \frac{\partial \theta}{\partial \mathrm{y}}+\mathrm{w} \frac{\partial \theta}{\partial \mathrm{z}}=\frac{1}{\operatorname{Pr}}\left(\frac{\partial^{2} \theta}{\partial \mathrm{y}^{2}}+\frac{\partial^{2} \theta}{\partial \mathrm{z}^{2}}\right)
\end{gathered}
$$

with corresponding boundary conditions

$$
\left.\begin{array}{c}
\mathrm{y}=0: \quad \mathrm{u}=1, \mathrm{v}=-(1-\varepsilon \cos \pi \mathrm{z}), \\
\mathrm{w}=0, \frac{\partial \theta}{\partial \mathrm{y}}=-1, \mathrm{y} \rightarrow \infty: \mathrm{u}=0: \\
\mathrm{v}=-1, \mathrm{w}=0, \mathrm{P}=\mathrm{P}_{\infty}, \theta=0
\end{array}\right]
$$

\section{Solution}

When the amplitude $\varepsilon<<1$, we assume the solution in the neighbourhood of the plate of the form

$$
\begin{gathered}
\mathrm{u}(\mathrm{y}, \mathrm{z})=\mathrm{u}_{0}(\mathrm{y})+\varepsilon \mathrm{u}_{1}(\mathrm{y}, \mathrm{z})+\ldots \\
\mathrm{v}(\mathrm{y}, \mathrm{z})=\mathrm{v}_{0}(\mathrm{y})+\varepsilon \mathrm{v}_{1}(\mathrm{y}, \mathrm{z})+\ldots \\
\mathrm{w}(\mathrm{y}, \mathrm{z})=\mathrm{w}_{0}(\mathrm{y})+\varepsilon \mathrm{w}_{1}(\mathrm{y}, \mathrm{z})+\ldots \\
\mathrm{p}(\mathrm{y}, \mathrm{z})=\mathrm{p}_{0}(\mathrm{y})+\varepsilon \mathrm{p}_{1}(\mathrm{y}, \mathrm{z})+\ldots \\
\theta(\mathrm{y}, \mathrm{z})=\theta_{0}(\mathrm{y})+\varepsilon \theta_{1}(\mathrm{y}, \mathrm{z})+\ldots
\end{gathered}
$$


When $\varepsilon=0$, substituting equation (14) in equations (8) to (13) and comparing the coefficient of like powers of $\varepsilon$ and neglecting those of $\varepsilon^{2}$, we get following equations constituted by the terms free from $\varepsilon$ :

$$
\begin{gathered}
\mathrm{v}_{0}^{\prime}=0 \\
\mathrm{u}_{0}^{\prime \prime}-\mathrm{v}_{0} \mathrm{u}_{0}^{\prime}=-\mathrm{Gr} \theta_{0} \\
\mathrm{v}_{0}^{\prime \prime}-\mathrm{v}_{0} \mathrm{v}_{0}^{\prime}=\mathrm{P}_{0}^{\prime} \\
\mathrm{w}_{0}^{\prime \prime}-\mathrm{v}_{0} \mathrm{w}_{0}^{\prime}=0 \\
\theta_{0}^{\prime \prime}-\mathrm{v}_{0} \operatorname{Pr} \theta_{0}^{\prime}=0
\end{gathered}
$$

where the primes denotes differentiation with respect to $\mathrm{y}$.

The corresponding boundary conditions become:

$$
\begin{aligned}
& \mathrm{y}=0: \quad \mathrm{u}_{0}=1, \mathrm{v}_{0}=-1, \mathrm{w}_{0}=0, \frac{\partial \theta_{0}}{\partial \mathrm{y}}=-1 \\
& \mathrm{y} \rightarrow \infty: \mathrm{u}_{0}=0: \mathrm{v}_{0}=-1, \mathrm{w}_{0}=0, \\
& \mathrm{P}_{0}=\mathrm{P}_{\infty}, \theta_{0}=0
\end{aligned}
$$

The solutions of equations (15) to (19) $(\operatorname{Pr} \neq 1)$ subject to the boundary conditions (20) are:

$$
\begin{gathered}
\mathrm{u}_{0}(\mathrm{y})=\mathrm{A}_{1} \mathrm{e}^{-\mathrm{y}}+\left(1-\mathrm{A}_{1}\right) \mathrm{e}^{-\operatorname{Pr} \mathrm{y}} \\
\theta_{0}(\mathrm{y})=\frac{1}{\operatorname{Pr}} \mathrm{e}^{-\operatorname{Pr} \mathrm{y}}
\end{gathered}
$$

with transverse velocity components $\mathrm{v}_{0}=-1, \mathrm{w}_{0}=0$ and the pressure $\mathrm{P}_{0}=\mathrm{P}_{\infty}$ where $\mathrm{A}_{1}=1+\frac{\mathrm{Gr}}{\mathrm{Pr}^{3}-\operatorname{Pr}^{2}}$ and $\operatorname{Pr} \neq 1$

This is the solution of a steady two-dimensional problem with constant suction and heat flux at the vertical plate. Taking into account the solutions of the transverse velocity components $\mathrm{v}_{0}$ and $\mathrm{w}_{0}$, when $\varepsilon \neq 0$, substituting equation (14) in equations (8) to (12) and comparing the coefficients of like powers of $\varepsilon$, neglecting those of $\varepsilon^{2}$, we get the terms as the coefficient of $\varepsilon$ give the following equations:

$$
\begin{gathered}
\frac{\partial \mathrm{v}_{1}}{\partial \mathrm{y}}+\frac{\partial \mathrm{w}_{1}}{\partial \mathrm{z}}=0 \\
\mathrm{v}_{1} \frac{\partial \mathrm{u}_{0}}{\partial \mathrm{y}}-\frac{\partial \mathrm{u}_{1}}{\partial \mathrm{y}}=\operatorname{Gr} \theta_{1}+\left(\frac{\partial^{2} \mathrm{u}_{1}}{\partial \mathrm{y}^{2}}+\frac{\partial^{2} \mathrm{u}_{1}}{\partial \mathrm{z}^{2}}\right) \\
-\frac{\partial \mathrm{v}_{1}}{\partial \mathrm{y}}=-\frac{\partial \mathrm{P}_{1}}{\partial \mathrm{y}}+\left(\frac{\partial^{2} \mathrm{v}_{1}}{\partial \mathrm{y}^{2}}+\frac{\partial^{2} \mathrm{v}_{1}}{\partial \mathrm{z}^{2}}\right) \\
-\frac{\partial \mathrm{w}_{1}}{\partial \mathrm{y}}=-\frac{\partial \mathrm{P}_{1}}{\partial \mathrm{z}}+\left(\frac{\partial^{2} \mathrm{w}_{1}}{\partial \mathrm{y}^{2}}+\frac{\partial^{2} \mathrm{w}_{1}}{\partial \mathrm{z}^{2}}\right) \\
\mathrm{v}_{1} \frac{\partial \theta_{0}}{\partial \mathrm{y}}-\frac{\partial \theta_{1}}{\partial \mathrm{y}}=\frac{1}{\operatorname{Pr}}\left(\frac{\partial^{2} \theta_{1}}{\partial \mathrm{y}^{2}}+\frac{\partial^{2} \theta_{1}}{\partial \mathrm{z}^{2}}\right)
\end{gathered}
$$

with the corresponding boundary conditions reduce to

$$
\left.\begin{array}{l}
\mathrm{y}=0: \quad \mathrm{u}_{1}=0, \mathrm{v}_{1}=-\cos \pi \mathrm{z}, \mathrm{w}_{1}=0, \frac{\partial \theta_{1}}{\partial \mathrm{y}}=0 \\
\mathrm{y} \rightarrow \infty: \mathrm{u}_{1}=0, \quad \mathrm{v}_{1}=0, \mathrm{w}_{1}=0, \theta_{1}=0
\end{array}\right]
$$

These are the set of linear partial differential equations which describe the three-dimensional flow.

In order to solve these equations, we separate the va- riables $\mathrm{y}$ and $\mathrm{z}$ in the following manner:

$$
\begin{aligned}
& \mathrm{u}_{1}=(\mathrm{y}, \mathrm{z})=\mathrm{u}_{11}(\mathrm{y}) \cos \pi \mathrm{z} \\
& \mathrm{v}_{1}(\mathrm{y}, \mathrm{z})=\mathrm{v}_{11}(\mathrm{y}) \cos \pi \mathrm{z} \\
& \mathrm{w}_{1}(\mathrm{y}, \mathrm{z})=-\frac{1}{\pi} \mathrm{v}_{11}^{\prime}(\mathrm{y}) \sin \pi \mathrm{z} \\
& \mathrm{P}_{1}(\mathrm{y}, \mathrm{z})=\mathrm{P}_{11}(\mathrm{y}) \cos \pi \mathrm{z} \\
& \theta_{1}(\mathrm{y}, \mathrm{z})=\theta_{11}(\mathrm{y}) \cos \pi \mathrm{z}
\end{aligned}
$$

Equations (30) and (31) are chosen so that the continuity equation (3.7.11) is satisfied. Substituting equations (29) to (33) in equations (24) to (28) and equating the coefficients of non-harmonic terms, we get the following equations:

$$
\begin{gathered}
\mathrm{u}_{11}^{\prime \prime}+\mathrm{u}_{11}^{\prime}-\pi^{2} \mathrm{u}_{11}=\mathrm{v}_{11} \mathrm{u}_{0}^{\prime}-\operatorname{Gr} \theta_{11} \\
\mathrm{v}_{11}^{\prime \prime}+\mathrm{v}_{11}^{\prime}-\pi^{2} \mathrm{v}_{11}=\mathrm{P}_{11}^{\prime} \\
\mathrm{v}_{11}^{\prime \prime \prime}+\mathrm{v}_{11}^{\prime \prime}-\pi^{2} \mathrm{v}_{11}^{\prime}=\pi^{2} \mathrm{P}_{11} \\
\theta_{11}^{\prime \prime}+\operatorname{Pr} \theta_{11}^{\prime}-\pi^{2} \theta_{11}=\operatorname{Pr} \mathrm{v}_{11} \theta_{0}^{\prime}
\end{gathered}
$$

with corresponding boundary conditions;

$$
\left.\begin{array}{l}
\mathrm{y}=0: \quad \mathrm{u}_{11}=0, \mathrm{v}_{11}=-1, \mathrm{v}_{11}^{\prime}=0, \frac{\partial \theta_{11}}{\partial \mathrm{y}}=0 \\
\mathrm{y} \rightarrow \infty: \mathrm{u}_{11}=0, \quad \mathrm{v}_{11}=0, \mathrm{P}_{11}=0, \theta_{11}=0
\end{array}\right]
$$

where the primes denote differentiation with respect to ' $y$ '.

From these equations the solutions of $\mathrm{u}_{1}, \mathrm{v}_{1}, \mathrm{w}_{1}, \mathrm{P}_{1}$ and $\theta_{1}$ $(\operatorname{Pr} \neq 1)$ under the corresponding boundary conditions are obtained as:

$$
\begin{aligned}
& \mathrm{u}_{1}= \frac{1}{\pi-\mathrm{n}}\left[\left\{\begin{array}{l}
-\mathrm{A}_{1}\left(\frac{\pi}{2 \mathrm{n}}-\frac{\mathrm{n}}{\pi}\right)+\mathrm{A}_{2} \\
-\mathrm{A}_{3}-\mathrm{A}_{4}
\end{array}\right\} \mathrm{e}^{-\mathrm{ny}}\right. \\
&+ \mathrm{A}_{1}\left\{\frac{\pi}{2 \mathrm{n}} \mathrm{e}^{-(\mathrm{n}+1) \mathrm{y}}-\frac{\mathrm{n}}{\pi} \mathrm{e}^{-(\pi+1) \mathrm{y}}\right\}-\mathrm{A}_{2} \mathrm{e}^{-(\mathrm{n}+\mathrm{Pr}) \mathrm{y}} \\
&+\left.\mathrm{A}_{3} \mathrm{e}^{-(\pi+\mathrm{Pr}) \mathrm{y}}+\mathrm{A}_{4} \mathrm{e}^{-\overline{\mathrm{n}} \mathrm{y}}\right] \cos \pi \mathrm{z} \\
& \mathrm{v}_{1}= \frac{1}{\mathrm{n}-\pi}\left\{\pi \mathrm{e}^{-\mathrm{ny}}-\mathrm{ne}^{-\pi \mathrm{y}}\right\} \cos \pi \mathrm{z} \\
& \mathrm{w}_{1}=\frac{\mathrm{n}}{\mathrm{n}-\pi}\left\{\mathrm{e}^{-\mathrm{ny}}-\mathrm{e}^{-\pi \mathrm{y}}\right\} \sin \pi \mathrm{z} \\
& \theta_{1}=\frac{\operatorname{Pr}}{\pi-\mathrm{n}}\left[\frac{\pi}{\mathrm{n}(\operatorname{Pr}+1)} \mathrm{e}^{-(\mathrm{n}+\mathrm{Pr}) \mathrm{y}}-\frac{\mathrm{n}}{\pi \operatorname{Pr}} \mathrm{e}^{-(\pi+\mathrm{Pr}) \mathrm{y}}\right. \\
&-\frac{1}{\overline{\mathrm{n}}}\left\{\frac{\pi(\mathrm{n}+\operatorname{Pr})}{\mathrm{n}(\operatorname{Pr}+1)}-\frac{\mathrm{n}(\pi+\operatorname{Pr})}{\pi \operatorname{Pr}}\right\} \mathrm{e}
\end{aligned}
$$

where $\mathrm{A}_{2}=\frac{\pi \mathrm{Gr}}{(\operatorname{Pr}+2 \mathrm{n}-1)}\left(\frac{1}{\operatorname{Pr}^{2}-\operatorname{Pr}}+\frac{1}{\mathrm{n}(\operatorname{Pr}+1)}\right)$,

$$
\begin{aligned}
& \mathrm{A}_{3}=\frac{\mathrm{n} \mathrm{Gr}}{\left(\operatorname{Pr}^{2}+2 \pi \operatorname{Pr}-\operatorname{Pr}-\pi\right)}\left(\frac{1}{\operatorname{Pr}-1}+\frac{1}{\pi}\right), \\
& \mathrm{A}_{4}=\frac{\mathrm{Gr} \operatorname{Pr}}{\bar{n}^{2}(\operatorname{Pr}-1)}\left(\frac{\pi(\mathrm{n}+\operatorname{Pr})}{\mathrm{n}(\operatorname{Pr}+1)}-\frac{\mathrm{n}(\pi+\operatorname{Pr})}{\pi \operatorname{Pr}}\right),
\end{aligned}
$$




$$
\begin{gathered}
\mathrm{n}=\frac{1}{2}\left[1+\left\{1+4 \pi^{2}\right\}^{1 / 2}\right], \\
\overline{\mathrm{n}}=\frac{1}{2}\left[\operatorname{Pr}+\left\{\operatorname{Pr}^{2}+4 \pi^{2}\right\}^{1 / 2}\right] .
\end{gathered}
$$

Substituting equations (21), (39) and (22), (43) in equation (14) for $u$ and $\theta$, we get the expressions for the main flow velocity and the temperature profiles. The main flow velocity and the temperature can now be expressed in terms of fluctuating part as:

$$
\begin{aligned}
& \mathrm{u}(\mathrm{y}, \mathrm{z})=\mathrm{u}_{0}(\mathrm{y})+\varepsilon \mathrm{u}_{1}(\mathrm{y}, \mathrm{z})=\mathrm{u}_{0}(\mathrm{y})+\varepsilon \mathrm{u}_{11} \cos \pi \mathrm{z} \\
& \theta(\mathrm{y}, \mathrm{z})=\theta_{0}(\mathrm{y})+\varepsilon \theta_{1}(\mathrm{y}, \mathrm{z})=\theta_{0}(\mathrm{y})+\varepsilon \theta_{11} \cos \pi \mathrm{z}
\end{aligned}
$$

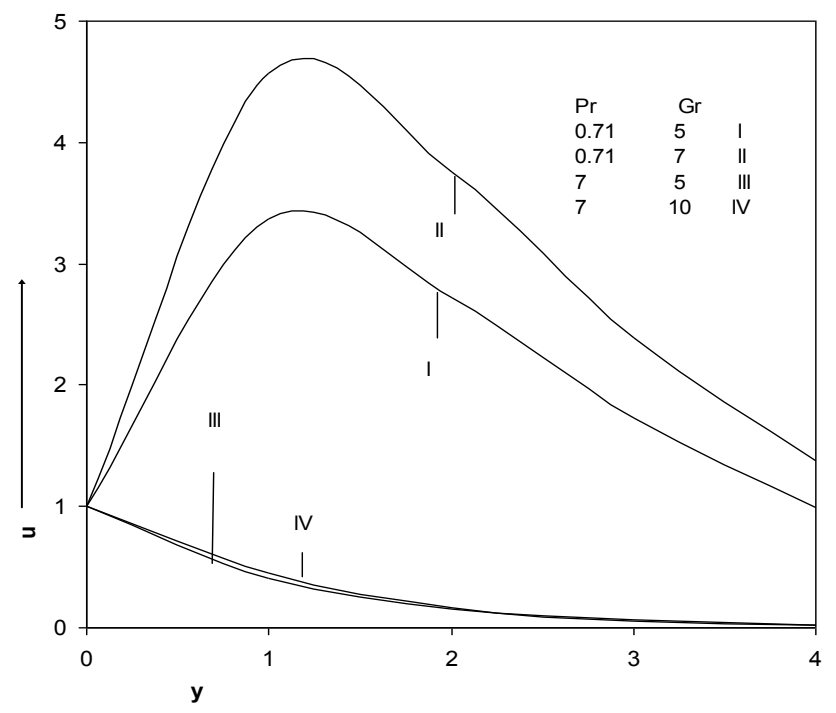

Figure 1. Velocity profiles for $\varepsilon=0.2, \mathrm{z}=0$.

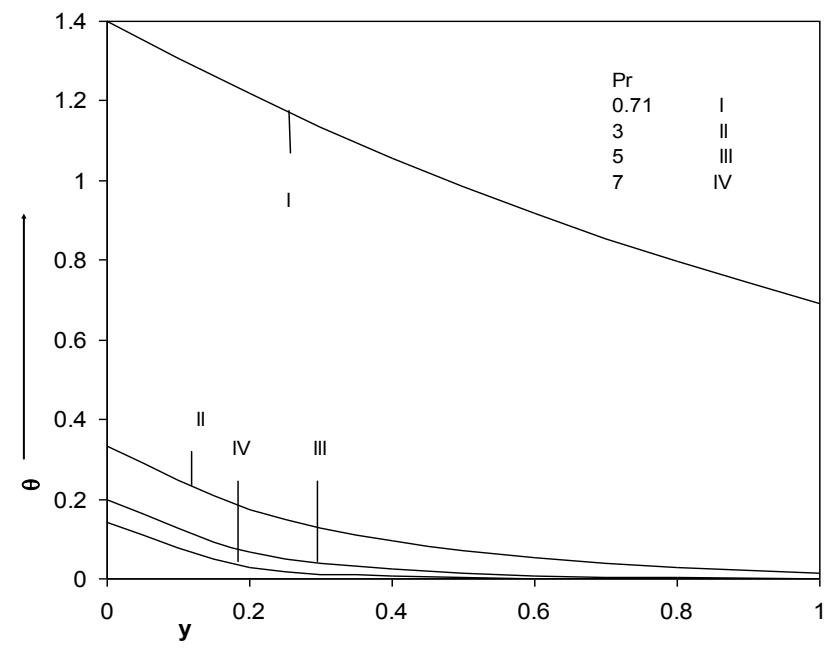

Figure 2. Temperature profiles for $\varepsilon=0.2, \mathrm{z}=0$.

\section{Results and Discussion}

Laminar three dimensional mixed convection flow past an infinite vertical porous plate with constant heat flux has been carried out in preceding section. The velocity field, temperature distribution and skin friction coefficient have been obtained and shown in figures for different values of parameters. We now discuss the important flow characteris- tics of the problem. The values of the Prandtl numbers are chosen as 0.71 and 7.0 approximately, which represent air and water respectively at $20^{\circ} \mathrm{C}$. The Grashof number $\mathrm{Gr}$ takes arbitrary positive values in order to investigate their effects on the flow fields. The velocity profiles are displayed on Figure 1, for various values of $\operatorname{Pr}(\neq 1)$ and Gr. It is interesting to note that the velocity increase with increasing Gr, which is true from the physical point of view because of buoyancy increases in the upper direction. In the case of air the fluid velocity increases with increase in Gr, until it attains its maximum value, after which it decreases. The fluid velocity takes its maximum value inside the thermal boundary layer due to the convection currents and as the distance from the vertical plate increases it decays to its limiting value. When $\operatorname{Pr}=7$, the value of the velocity is very small and approaches to zero as the distance from the surface increases. The variations in $\mathrm{Gr}$ do not affect them significantly. An examination of Figure 2 shows that the temperature profiles collapse onto the similar curves as the Prandtl number increases. It is found that the temperature is maximum on the plate and farther from the wall it decays to zero. It is clear from figure that the thermal boundary layer becomes very thin as Pr increases. The physical reason is that the high Prandtl number fluid has a relatively low thermal conductivity which oppose conduction and thereby increase the variations. Thus, results in a reduction in the thermal boundary layer and an increase in the convection heat transfer at wall.

From the velocity component $\mathrm{u}$, we can now calculate the skin-friction in the main flow direction in the non-dimensional form as

$$
\tau_{\mathrm{x}}=\tau_{\mathrm{x}}^{*} / \rho^{*} \mathrm{U}_{0} \mathrm{~V}_{0}=\left(\frac{\partial \mathrm{u}}{\partial \mathrm{y}}\right)_{\mathrm{y}=0}
$$

Hence the sinusoidal skin friction with the help of (44) is

$$
\begin{aligned}
& \tau_{\mathrm{x}}=-1+\frac{\mathrm{Gr}}{\operatorname{Pr}}+\frac{\varepsilon}{\pi-\mathrm{n}}\left[\begin{array}{l}
-\mathrm{A}_{1}\left(\frac{\pi}{2 \mathrm{n}}+\pi-\mathrm{n}\right)+ \\
\mathrm{A}_{2} \operatorname{Pr}+\mathrm{A}_{3}(\mathrm{n}-\pi-\operatorname{Pr})
\end{array}\right. \\
& \left.+\mathrm{A}_{4}(\mathrm{n}-\overline{\mathrm{n}})\right] \cos \pi \mathrm{z}
\end{aligned}
$$

Figure 3 exhibits the sinusoidal skin-friction in the main flow direction for different values of $\operatorname{Pr}(\neq 1)$ and Gr. Increasing the Prandtl number the value of skin-friction decreases significantly. Physically this is true because the increase in the Prandtl number is due to increase in the viscosity of the fluid, which makes the fluid thick and hence a decrease in the velocity of the fluid. The skin-friction increases with increase in Gr only. The values of the skin-friction are less in the case of water than those in the case of air.

Finally we note that since the Grashof number involve the suction velocity $\mathrm{V}_{0}$, the results discussed above and depicted in Figures 1-3 corresponds also to the variations in the suction velocity at the porous plate in the manner $\mathrm{V}_{0}^{3} \alpha \mathrm{Gr}^{-1}$. 


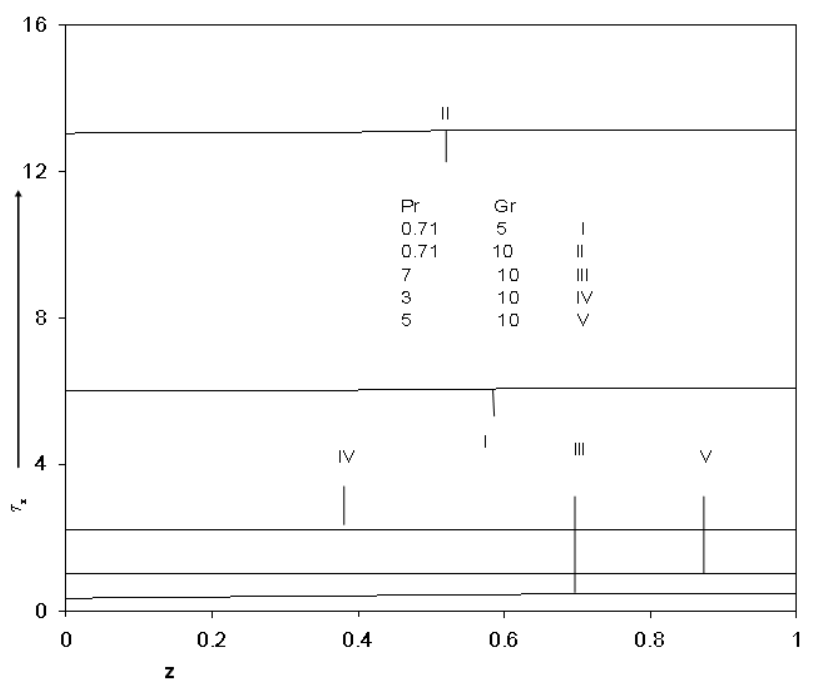

Figure 3. Sinusoidal skin-friction for $\varepsilon=0.2$.

\section{REFERENCES}

[1] Lachmann, G. V., 1961, Boundary layer and flow control Its Principles and Applications, Pergamon Press, Oxford

[2] Ostrach, S., 1952, An anlaysis of laminar free-convection flow and heat transfer about a flat plate parallel to the direction of the generating body force, NACA TN No.2635

[3] Ostrach, S., 1953, New aspects of natural convection heat transfer, Trans. Am. Soc. Mech. Eng., 75, 1287

[4] Stewartson ,K., Jones, L. T., 1957, The heated vertical plate at high Prandtl number, Aero.Sci., 24, 379

[5] Sparrow, E. M., Gregg, J. L., 1956, Laminar free convection from a vertical plate with uniform heat flu., J. Heat Transfer, 78,435

[6] Sparrow, E. M., Gregg, J. L., 1958, Similar solution for free convection from a nonisothermal vertical plate, J. Heat Transfer, 80, 379

[7] Mabuchi, I., 1963, The effect of blowing or suction on heat transfer by free convection from a vertical flat plate, Bull. JSME, 6, .223

[8] Riley, D. S. and Drake, D. G. (1975): "Higher approximations to the free-convection flow from a heated vertical flat plate". Appl. Sci. Res., Vol.30, p.193

[9] Berezovsky, A. A., Martynenko, O. G., Sokovishm, Yu. A., 1977, Free convective heat transfer on a vertical semi-infinite plate, J. Engng. Phys., 33, 32

[10] Na, T. Y., 1978, Numerical solution of natural convection flow past a non-isothermal vertical flat plate, Appl. Sci. Res., 33,519

[11] Dey, J., Nath, G. 1981, Mixed convection flow on vertical surfaces, Warme und Stoffubertragung 15, 279

[12] Kawase, Y., Ubrecht, J. J. 1984, Approximate solution to the natural convection heat transfer from a vertical plate, Int. Comm. Heat Mass Transfer, 11, 143
[13] Martynenko, O. G., Berezovsky, A. A., Sokovishin, Yu. A, 1984, Laminar free-convection from a vertical plate, Int. J. Heat Mass Transfer. .27, 869

[14] Weiss, Y., Ahoran, Y., Shai, I. 1994), Natural convection on a vertical flat plate at general boundary conditions, Proc. Int. Heat Transfer Conference, 10th, 1

[15] Pantokratoras, A., 2001, Laminar free convection heat transfer from a vertical isothermal plate to water at low temperature with variable Physical properties, Int. Journal of Heat and Fluid flow, 22, 666

[16] Pantokratoras, A., 2002, Laminar free convection over a vertical isothermal plate with uniform blowing or suction in water with variable physical properties, Int. J. Heat Mass Transfer, .45, 963

[17] Gersten, K., Gross, J. F., 1974, Flow and heat transfer along a plane wall with periodic suction, ZAMP, 25, 339

[18] Singh, P., Sharma, V. P., Misra, U. N., 1978, Three-dimensional free convection flow and heat transfer along a porous vertical plate, Appl. Sci. Res., .34, 105

[19] Bejan, A., 1995, Convective heat transfer, John Wiley \& Sons, Inc

[20] Merkin, J. H., Mahmood, T., 1989, Mixed convection boundary layer similarity solutions for prescribed wall heat flux, ZAMP, 40, .51

[21] Lee, S., Yovanovich, M. M., 1992, Linearization of natural convection from a vertical plate with arbitrary heat flux distributions, J. Heat Transfer, 14, 909

[22] Malarvizhi, G., Ramanaiah, G., Pop, I., 1994, Free and mixed convection about a vertical plate with prescribed temperature or Heat Flux, ZAMM, 74, 129

[23] Burak, V. S., Volkov, S. V., Martynenko, O. G., Khramtsov, P. P., Shikh, I. A. 1995, Free convection heat transfer on a vertical surface with heat flux discontinuity, Int. J. Heat Mass Transfer, 38 (1), 155

[24] Pantokratoras, A., 2003, Laminar free convection in water with variable physical properties adjacent to a vertical plate with uniform heat flux, Int. J. Heat Mass Transfer, 46, 725

[25] Chaudhary R. C., Sharma B. K., 2003, Injection and suction effects on three dimensional unsteady flow and heat transfer between two parallel porous plates, Matematicas, XI No 1, 2 Dic., $45-55$

[26] Sharma Bhupendra Kumar., Chaudhary R. C, Agarwal Mamta, 2007, Radiation effect on temperature distribution in three-dimensional Couette flow with injection or suction, Appl. Maths. and Mech., 28(3), 309-316

[27] Sharma P. K., Sharma, Bhupendra Kumar, Chaudhary R. C, 2008, Three-dimensional unsteady mixed convection and mass transfer flow with periodic temperature, DIRASAT, $35(1), 9-23$

[28] Sharma Bhupendra Kumar, Sharma P. K., and Chaudhary R. C, 2009, Effects of fluctuating surface temperature and concentration on unsteady convection flow past an infinite vertical plate with constant suction, Heat Transfer Research, 40(6), 505-519

[29] Sharma B. K., Sharma P. K., T. Chand, 2011, Radiation ef- 

Vertical Plate with Constant Surface Heat Flux

fect on temperature distribution in three-dimensional Couette flow with injection or suction and heat source, Int. J. of Ap- plied Mechanics and Engineering, 16, No.2, ,531-542 